\title{
BIMETALLIC AU/AG METAL SUPERSTRUCTURES FROM MACROMOLECULAR METAL COMPLEXES IN SOLID-STATE
}

\author{
CARLOS DIAZ ${ }^{*}$, MARIA LUISA VALENZUELA ${ }^{b}$ AND DANIELA BOBADILLA ${ }^{a}$ \\ a Departamento de Química, Facultad de Química, Universidad de Chile. Las Palmeras 3425, Nuñoa, casilla 653, Santiago de Chile, Chile. \\ ${ }^{b}$ Universidad Andres Bello, Departamento de Ciencias Química, Facultad de Ciencias Exactas. Av. Republica 275, Santiago, Chile.
}

(Received: June 25, 2013 - Accepted: September 25, 2013)

\begin{abstract}
Novel bimetallic $\mathrm{Au} / \mathrm{Ag}$ superstructures have been prepared from solid-state pyrolysis of the macromolecular complexes Chitosan(MLn/M'Ln) y PSP4-PVP $\times\left(\mathrm{MLn} / \mathrm{M}\right.$ 'Ln)n with $\mathrm{MLn}=\mathrm{AuCl}_{3}$ and $\mathrm{M}^{\prime} \mathrm{Ln}=\mathrm{Ag}\left(\mathrm{CF}_{3} \mathrm{SO}_{3}\right)$.The characterization was made from XRD (X-ray diffraction of powder), SEM and EDS analysis. Morphologies are influenced by both the nature of the polymer and the metal/polymer, molar ratio of the polymer precursor. EDS analysis suggests a core/shell $\mathrm{Au} / \mathrm{Ag}$ structure for the materials. A probable mechanism of the formation of these superstructures is discussed. Although separated reports of metallic superstructures of $\mathrm{Au}$ or $\mathrm{Ag}$ have been recently described, the here reported are the first bimetallic $\mathrm{Au} / \mathrm{Ag}$.
\end{abstract}

Key words: Superstructures, Macromolecular complexes, metallic Au and Ag, Pyrolysis

\section{INTRODUCTION}

Noble metal structures usually can be obtained in both as bulk and/ or nanostructured materials ${ }^{1-3}$. However a third form, called 3D supracrystals or superlattices have recently emerged ${ }^{4-6}$. These can be obtained by destabilization of the Au solution nanoparticles, usually by elimination of the solvent These materials have interesting collective intrinsic properties. The few reported preparation methods for this type of materials have been developed in solution and not solid-state approximation has been done. Thus, among the few reports on this type of materials no bimetallic $\mathrm{Au} / \mathrm{Ag}$ superstructures have been reported, only Au or Ag superlattices ${ }^{4-6}$. Here we report a solid-state method to prepare $\mathrm{Au} / \mathrm{Ag}$ superstructures from pyrolysis of the macromolecular precursors Chitosan(MLn/M'Ln) y PSP-4-PVP $\times\left(\mathrm{MLn} / \mathrm{M}^{\prime} \operatorname{Ln}\right) n$ with $\mathrm{MLn}=\mathrm{AuCl}_{3}$ and $\mathrm{M}^{\prime} \mathrm{Ln}=\mathrm{AgCF}_{3} \mathrm{SO}_{3}, \mathrm{PSP}-4-\mathrm{PVP}=$ poly[styrene-block-(4-vinylpyridine)].

We have previously reported a solid-sate method to prepare metallic and/ or metal oxides nanostructured materials (see Figure 1). Solid-state pyrolysis of organometallic derivatives of cyclic and/or polyphosphazenes at $800{ }^{\circ} \mathrm{C}$ affords metallic nanostructures of the type $\mathrm{M}^{\circ}, \mathrm{M}_{\mathrm{x}} \mathrm{O}_{\mathrm{y}}$ and $\mathrm{M}_{\mathrm{x}} \mathrm{P}_{\mathrm{y}} \mathrm{O}_{z}{ }^{7-21}$.

However, due to the presence of phosphorus in the polymeric chain, the nanostructured materials usually involve phosphates and/or pyrophosphates metallic phases ${ }^{16}$. When the cyclic and/or polyphosphazenes have coordinated two organometallic fragments as $\mathrm{CpFe}(\mathrm{dppe})^{+}$and $\mathrm{TlPF}_{6}$, the bimetallic core/ shell $\mathrm{Fe}_{2} \mathrm{Fe}_{5}\left(\mathrm{P}_{2} \mathrm{O}_{7}\right)_{4} / \mathrm{Tl}_{3} \mathrm{P}_{3} \mathrm{O}_{9}$ nanoparticles are obtained ${ }^{21}$ after pyrolysis. Therefore, if we want to obtain pure bimetallic nanoparticles, a polymer not containing phosphorus within the polymeric chain could be desirable. It is expected that phosphorus-less organic polymers have the potential to be good solid-state templates of metallic and organometallic-macromolecular complexes during their pyrolysis. We have selected Chitosan and PSP-4-PVP due to their ability to coordinate ion metals through the nitrogen atoms to form macromolecular metal-polymer complexes precursors ${ }^{22-29}$.

\section{EXPERIMENTAL}

$\mathrm{AuCl}_{3}$ and $\mathrm{Ag}\left(\mathrm{CF}_{3} \mathrm{SO}_{3}\right)$, PSP-co-4-PVP and Chitosan were purchase from Aldrich and used as received. All the reactions were performed in $\mathrm{CH}_{2} \mathrm{Cl}_{2}$ as solvent and reaction time was one week.

\section{Precursors Synthesis}

General Procedure Chitosan(MLn/M'Ln)n

In a typical synthesis, the respective metallic salts, $\mathrm{AuCl}_{3}$ and $\mathrm{Ag}\left(\mathrm{CF}_{3} \mathrm{SO}_{3}\right)$ were added in a Schlenk tube over the $\mathrm{CH}_{2} \mathrm{Cl}_{2}$ solvent under magnetic stirring and then the respective Chitosan amount according the 1:1, 1:5 or molar ratio. Reaction time and other details for each metallic salts reaction are given in Table 1. After this the supernatant solution (if the solid decanted) was extracted with a syringe and the solid dried under reduced pressure to give a yellow-red solid (Table 1). Owing to their insolubility characterization of the precursors was made only by elemental analysis and IR spectroscopy. Coordination was confirmed by the behavior of the broad $v(\mathrm{OH})$ in Chitosan ${ }^{20}$ which becomes unfolded upon coordination, and exhibiting a new band around $3100 \mathrm{~cm}^{-1}$. PSPco-4-PVP coordination was evidenced by the appearance of a characteristic band in the range $1600-1650 \mathrm{~cm}^{-1}$ corresponding to coordinate pyridine ${ }^{10,20}$.

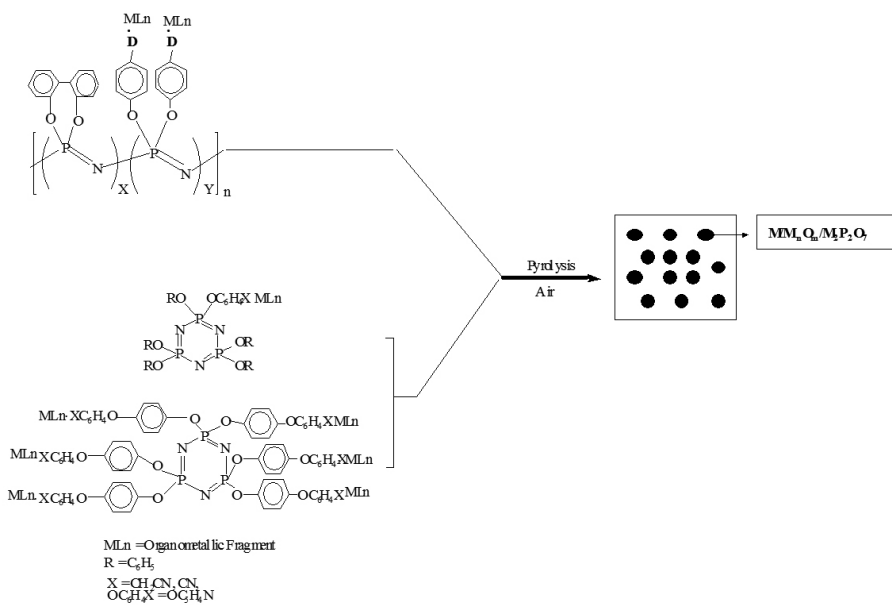

Figure 1 Schematic representation of the solid-state method to obtain nanostructured materials from oligomeric and polymeric precursors.

\section{General Procedure PSP-4-PVP/( MLn/M'Ln)n}

In a typical synthesis the respective metallic salt $\mathrm{AuCl}_{3}$ and $\mathrm{Ag}\left(\mathrm{CF}_{3} \mathrm{SO}_{3}\right)$ were added in a Schlenk tube over the $\mathrm{CH}_{2} \mathrm{Cl}_{2}$ solvent under magnetic stirring and then the respective Poly(styrene-co-4-vinylpyridine) amount according to the 1:1 or 1:5 molar ratio. After approximate 6 days the supernatant solution (provided the solid decanted) was extracted with a syringe and the solid dried under reduced pressure to give a solid with diverse colors. In some cases the polymer undergoes an extensive gel formation. In such case the solvent was eliminated at reduced pressure using a high vacuum pump and/or using a furnace with vacuum. PSP-co-4-PVP coordination was evidenced by the appearance of a characteristic band in the range 1600-1650 cm-1 corresponding to coordinate pyridine ${ }^{10,20}$.

Elemental analyses (\%) : (1) C,10.93; H, $1.71 ; \mathrm{N}, 1.8 ; \mathrm{S}, 3.91$. (2) C, 24.12; H, 3.88; N, 4.70; S 3.37. (3) C, 7.3; H, 0.74; N, 1.08; S, 1.22. (4) C, $38.74 ; \mathrm{H}, 3.2 ; \mathrm{N}, 5.9 ; \mathrm{S}, 3.59$. Owing the complex and uncertain exact formula of the precursor, the calculated $\mathrm{C}, \mathrm{H}$ and $\mathrm{N}$ content was not possible to estimate. 
Table 1. Experimental details of the precursors formation ${ }^{\mathrm{a}}$

\begin{tabular}{|c|c|c|c|c|c|c|}
\hline No & Precursor & Ratio $^{b}$ & Polymer(g) & $\operatorname{Au}(g)^{c}$ & $\operatorname{Ag}(g)^{d}$ & Color of the product \\
\hline 1 & Chitosan(MLn/M'Ln $)_{n}$ & $1: 1$ & 0.225 & 0.4 & 0.34 & Bright brown-yellow \\
\hline 2 & Chitosan(MLn/M'Ln $)_{n}$ & $1: 5$ & 1.16 & 0.4 & 0.34 & Bright brown-yellow \\
\hline 3 & PSP-4-PVP×(MLn/M'Ln)n & $1: 1$ & 0.145 & 0.4 & 0.35 & Bright yellow \\
\hline 4 & PSP-4-PVP $\times\left(M L n / M^{\prime} L n\right) n$ & $1: 5$ & 0.698 & 0.4 & 0.34 & Bright yellow \\
\hline
\end{tabular}

${ }^{a}$ In all the reactions a solvent volume of $40 \mathrm{~mL}$ was used.

${ }^{b}$ Polymer/metal relation

${ }^{\mathrm{c}} \mathrm{AuCl}_{3}$

${ }^{\mathrm{d}} \mathrm{Ag}\left(\mathrm{CF}_{3} \mathrm{SO}_{3}\right)$

\section{Pyrolysis}

The pyrolysis experiments were conducted by pouring a weighed portion $(0.05-0.15 \mathrm{~g})$ of the respective precursor into aluminum oxide boats that were placed in a furnace (Labtech LEF-10 oven) under a flow of air, heating from $25^{\circ} \mathrm{C}$ to upper temperature limits of $300{ }^{\circ} \mathrm{C}$, and then to $800{ }^{\circ} \mathrm{C}$, followed by annealing for 2-4 $\mathrm{h}$ and at rates of $10^{\circ} \mathrm{C} \mathrm{min}^{-1}$ in each case.

\section{Characterization of the pyrolytic products}

Solid pyrolytic samples were characterized by X-Ray diffraction of powders (XRD) and scanning electron microscopy (SEM). SEM images were acquired with a JSM-6380LV, Jeol Ltda. microscope, with an acceleration potential of $20 \mathrm{keV}$. Energy dispersive X-ray analysis (EDAX) was performed on a NORAN Instrument micro-probe attached to a JEOL 5410 scanning electron microscope. X-ray diffraction (XRD) was conducted at room temperature on a Siemens D-5000 diffractometer with $\theta-2 \theta$ geometry. The XRD data was collected using $\mathrm{Cu}-\mathrm{K} \alpha$ radiation $(40 \mathrm{kV}, 30 \mathrm{~mA})$. FTIR measurements were performed on a Perkin Elmer FTIR spectrophotometer model Spectrum BXII using KBr pellets. Elemental analysis were performed on a FISONS INSTRUMENTS, model EA 1108 CHNS-O instruments (Pontificia Universidad Catolica de Chile )

\section{RESULTS AND DISCUSSION}

Figure 2 shows the XRD patters diffraction of the pyrolytic products from the precursors Chitosan $\left(\mathrm{AuCl}_{3} / \mathrm{Ag}\left(\mathrm{CF}_{3} \mathrm{SO}_{3}\right)\right)_{\mathrm{n}}$ and PSP-4-PVP $\times\left(\mathrm{AuCl}_{3} /\right.$ $\left.\mathrm{Ag}\left(\mathrm{CF}_{3} \mathrm{SO}_{3}\right)_{\mathrm{n}}\right)_{\mathrm{n}}$ precursors with molar ratios $1: 1$. The lattices constants for $\mathrm{Au}$ and $\mathrm{Ag}$ are very similar so their XRD are totally overlapped preventing discrimination of Au-Ag bimetallic phase from either monometallic phase based on the XRD patterns ${ }^{30-32}$. Therefore the presence of core/shell or alloys Au/ $\mathrm{Ag}$ structures can be distinguished by TEM imaging ${ }^{33,34}$ or by Uv-visible spectroscopy ${ }^{35-37}$. The presence of $\mathrm{Au}$ and $\mathrm{Ag}$ can be confirmed by EDS analyses ${ }^{32}$.

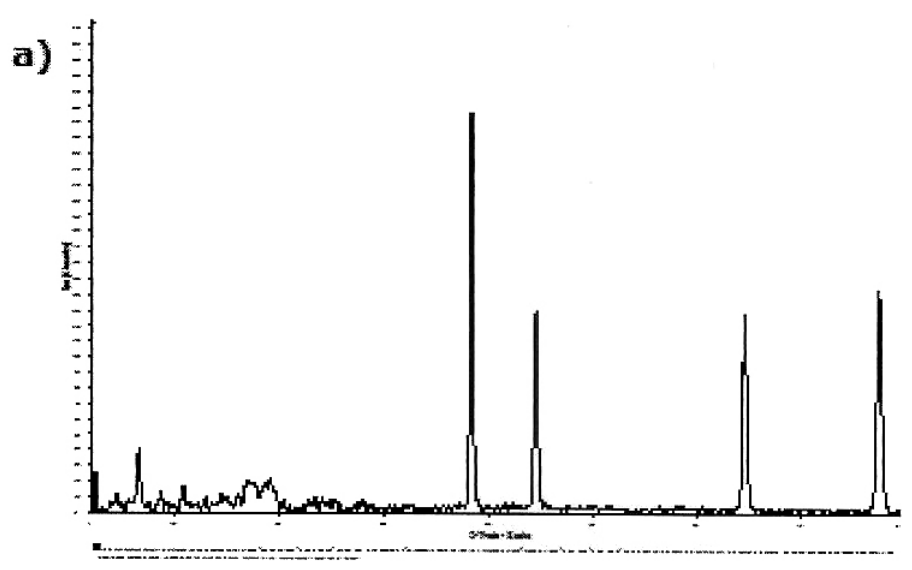

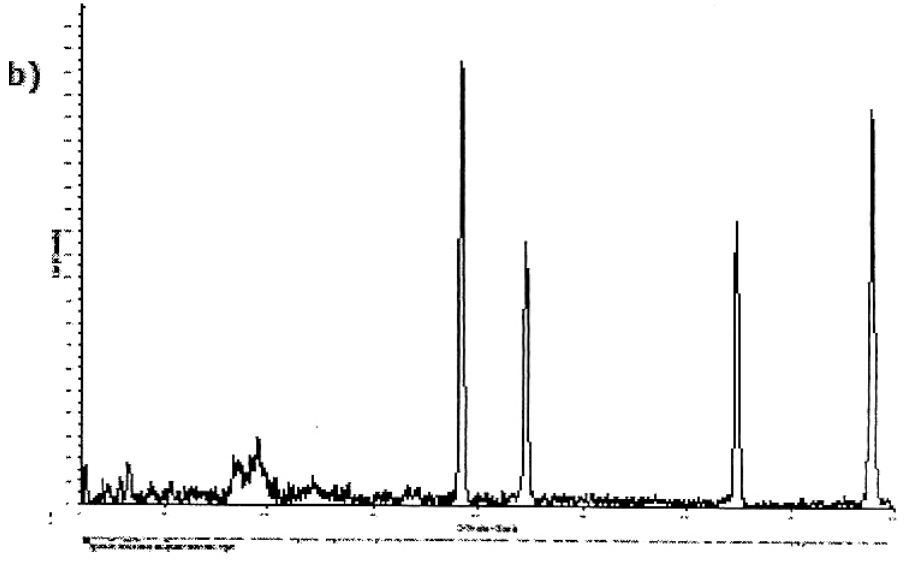

Figure 2. XRD patterns of pyrolytic products from Quitosano $\left(\mathrm{AuCl}_{3} /\right.$ $\left.\mathrm{Ag}\left(\mathrm{CF}_{3} \mathrm{SO}_{3}\right)\right)_{\mathrm{n}}$ a) and PSP-4-PVP $\times\left(\mathrm{AuCl}_{3} / \mathrm{Ag}\left(\mathrm{CF}_{3} \mathrm{SO}_{3}\right)_{n}\right) \mathrm{n}$ b), both with molar ratio $1: 1$.

Using this technique is normally possible only when the $\mathrm{Au} / \mathrm{Ag}$ nanoparticles are prepared in solution.

In our case the characterization using these two techniques is not possible because the pyrolytic products are very hard solid materials and they cannot be ground or cut into thin films for to be mounted on the grid of the TEM apparatus or be mounted as a power in the UV-visible reflectance diffuse holder. However by SEM-EDS analysis ${ }^{32}$ a possible structure of $\mathrm{Au} / \mathrm{Ag}$ bimetallic materials can be proposed. Figure 3 shows the SEM image of the pyrolytic products from all precursors. As can be viewed from Figure 3 the morphology of the product depends on both the nature of the polymer (ie compare Figure $3 \mathrm{a}$ with $3 b$ and $3 c$ with $3 d$ ) and on the ratio formation of the precursor (ie compare Figure $3 \mathrm{a}$ with $3 \mathrm{c}$ and $3 \mathrm{~b}$ with $3 \mathrm{~d}$ ). For a constant molar ratio metal/polymer ie. 1:1 the PSP-4-PVP induces most porous materials than Chitosan. On the other hand for a constant polymer (PSP-4-PVP or Chitosan), the 1:1 metal/polymer ratio induces a most dense material than with a 1:5 ratio.

This can be due to the most near linked $\mathrm{Au}$ and $\mathrm{Ag}$ centers in the polymeric chain in the 1:1 ratio of the both polymeric precursors. However these conclusions could be valid, although the Figure $3 \mathrm{~d}$ was taken in a greater magnification.

The presence of gold and silver in the pyrolytic materials was confirmed by EDS analysis. As shown in Figure 4a,b for the pyrolytic products from 1:1 PSP-4-PVP $\times\left(\mathrm{AuCl}_{3} / \mathrm{Ag}\left(\mathrm{CF}_{3} \mathrm{SO}_{3}\right)_{n}\right) \mathrm{n}$ and 1:1 Chitosan $\left(\mathrm{AuCl}_{3} / \mathrm{Ag}\left(\mathrm{CF}_{3} \mathrm{SO}_{3}\right)\right)_{\mathrm{n}}$ precursors, the presence of gold and silver is evident. For the other pyrolytic product similar SEM/EDS images were observed. The nature of the $\mathrm{Au} / \mathrm{Ag}$ bimetallic materials become clear by observing the quantitative ESD analysis where an approximate content $\mathrm{Au} / \mathrm{Ag}$ of $2: 1$ characteristic of core/shell ${ }^{38,39}$ was observed see Figure 5. A possible representation of these are given in Figure 6. 
a)

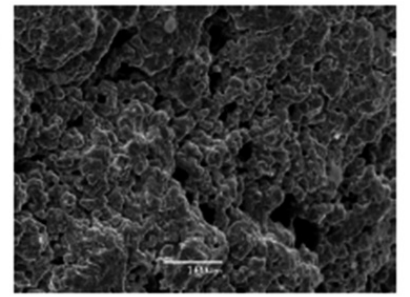

c)

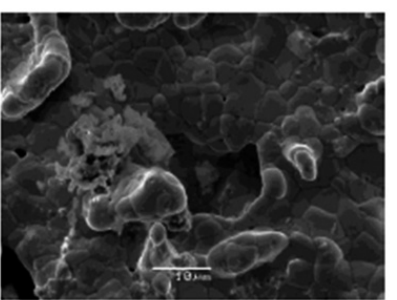

b)

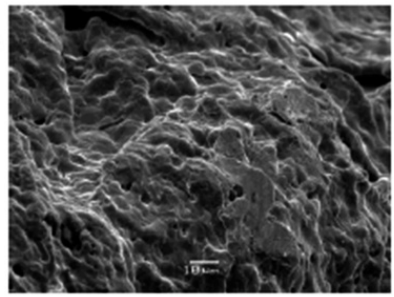

d)

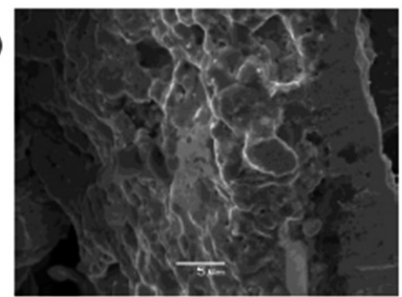

Figure 3 SEM images of the pyrolytic products from precursors : a) PSP4-PVP•( $\left.\mathrm{AuCl}_{3} / \mathrm{Ag}\left(\mathrm{CF}_{3} \mathrm{SO}_{3}\right) \mathrm{n}\right) \mathrm{n} 1: 1 ;$ b) Chitosan $\left.\bullet \mathrm{AuCl}_{3} / \mathrm{Ag}\left(\mathrm{CF}_{3} \mathrm{SO}_{3}\right)\right)$ n 1:1 ; c) PSP-4-PVP• $\left.\left(\mathrm{AuCl}_{3} / \mathrm{Ag}\left(\mathrm{CF}_{3} \mathrm{SO}_{3}\right) \mathrm{n}\right) \mathrm{n} 1: 5 \mathrm{~d}\right)$ ChitosanAuCl $\left.\mathrm{Ag}_{3} / \mathrm{Ag}^{3}\left(\mathrm{CF}_{3} \mathrm{SO}_{3}\right)\right)$ n $1: 5$

a)

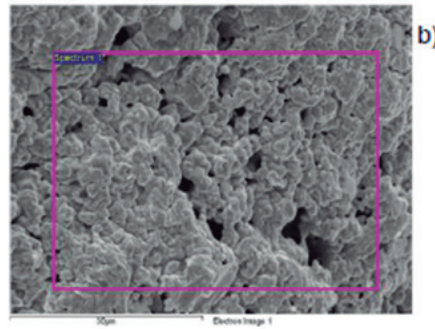

c)

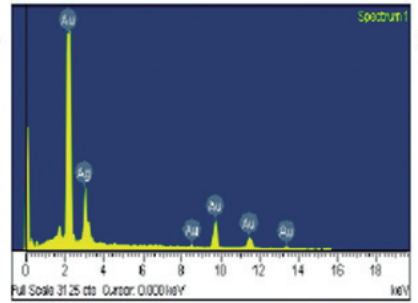

Figure 4 a) SEM image and their c) EDS analysis for the pyrolytic product from 1:1 from 1:1 PSP-4-PVP• $\left(\mathrm{AuCl}_{2} / \mathrm{Ag}\left(\mathrm{CF}_{3} \mathrm{SO}_{3}\right) \mathrm{n}\right) \mathrm{n}$ precursor $(\mathrm{a}, \mathrm{c})$ and for 1:1 Quitosano $\bullet\left(\mathrm{AuCl}_{3} / \mathrm{Ag}\left(\mathrm{CF}_{3} \mathrm{SO}_{3}\right)\right)$ n $(\mathrm{b}, \mathrm{d})$.

A linear EDS scanning for a line through a zone of the pyrolytic product from 1:1 PSP-4-PVP• $\left(\mathrm{AuCl}_{3} / \mathrm{Ag}\left(\mathrm{CF}_{3} \mathrm{SO}_{3}\right)\right)$ precursor is shown in Figure 5. It can be observed a double content of the Au in relation to the Ag content which could be indicative of a core/shell structure ${ }^{38}$, see Figure 6 . The junction of these core/shell nanoparticles in a 3D manner would give rise to the observed "superstructures" by SEM.

Monolithic nanoporous gold structures are interesting materials with unusual application and peculiar properties such as mechanical strength and stiffness ${ }^{40,41}$. Recently it was reported that Au disks of nanoporous morphology exhibit a $10^{8}$ factor surface enhanced Raman scattering ${ }^{42}$. The Au/Ag bimetallic materials reported here could then have some

SERS (Surface-enhanced Raman scattering) activity which could be enhanced in relation to $\mathrm{Au}$ and $\mathrm{Ag}$ individual due to some cooperative bimetallic effect.
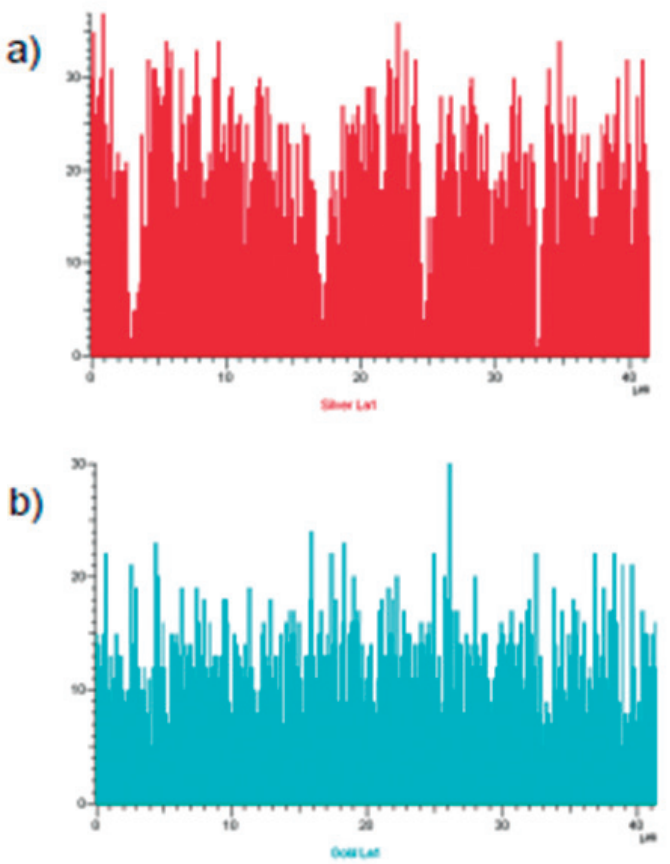

c)

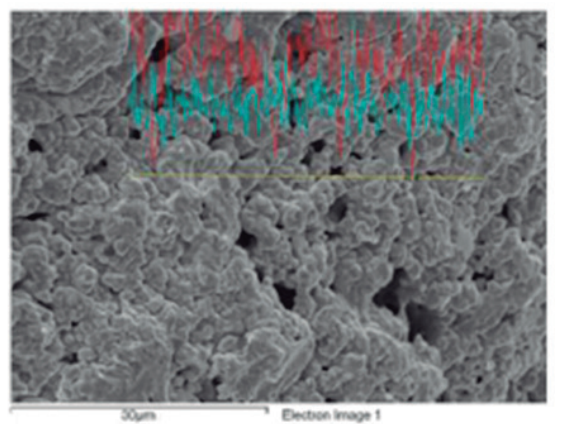

Figure 5. Au a) and $\mathrm{Ag}$ b) profile content for the pyrolytic product from PSP-4-PVP• $\left(\mathrm{AuCl}_{3} / \mathrm{Ag}\left(\mathrm{CF}_{3} \mathrm{SO}_{3}\right) \mathrm{n}\right) \mathrm{n}$ 1:1 precursor in the line marked by yellow line in $\mathrm{c})$.

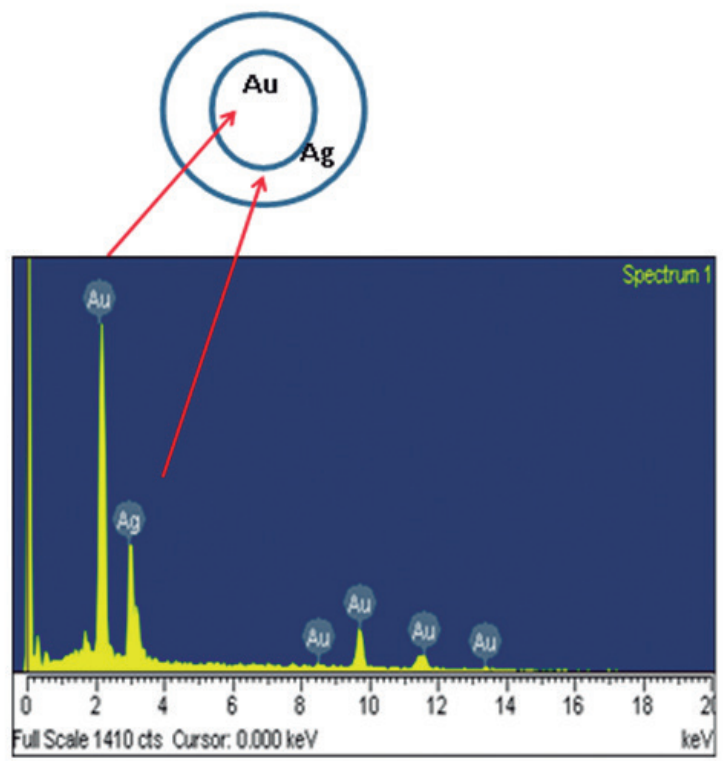

Figure 6. Representative structure of the Core/shell $\mathrm{Au} / \mathrm{Ag}$ nanoparticles 


\section{Probable mechanism formation}

The most likely mechanism for the formation of the $\mathrm{Au} / \mathrm{Ag}$ superstructures may be similar to mechanisms that have been previously established as general for the solid-state pyrolysis of metallic and organometallic derivatives cyclicoligomer-phosphazene and polyphosphazense $\mathrm{e}^{7-21}$. Figure 7 shows a schematic representation of the probable formation mechanism of the pyrolytic product.
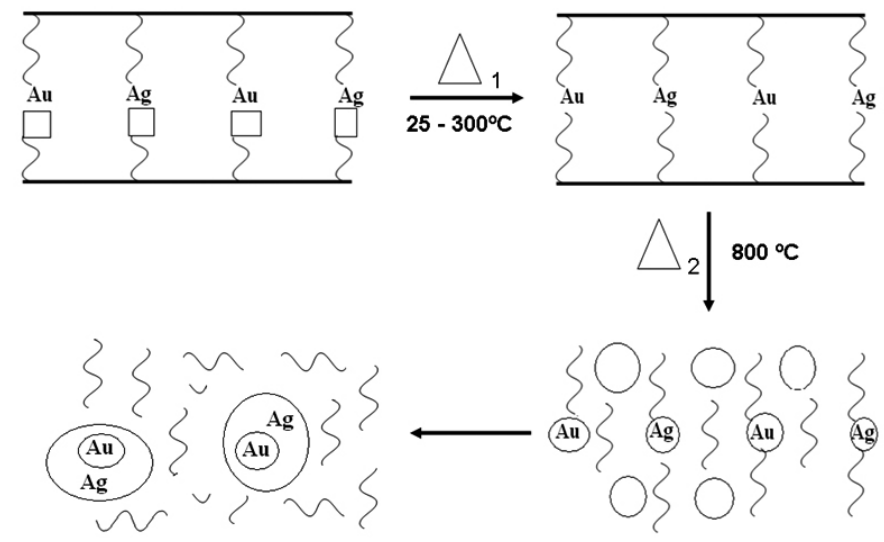

Figure 7. schematic representation of the probable formation mechanism of the pyrolytic products.

The first step involves the cross-linking ${ }^{13}$ of the polymer induced by the coordination by the PSP-co-4-PVP or Chitosan polymer chains to the metal centers during the initial annealing step, followed by the carbonization of the organic matter to produce holes were the metal centers begin to coarsen and grow $^{43}$. Carbonization of the organic matter usually occurs during pyrolysis of metallic and organometallic derivatives of polymers around $350{ }^{\circ} \mathrm{C}{ }^{43}$. Some incomplete combustion always produces some $\mathrm{CO}^{44}$ which reduces the metallic $\mathrm{Au}(\mathrm{I})$ and $\mathrm{Ag}(\mathrm{I})$ salts to $\mathrm{Au}$ and $\mathrm{Ag}$ which bind together. Subsequently join of these core/shell nanoparticles produce the 3D "superstructures".

Also in the combustion process a sudden loss of nitrogen -arises from the pyridine groups of PSP-co-4-PVP or $\mathrm{NH}_{2}$ Chitosan- induces foamy materials ${ }^{44}$.

\section{CONCLUSIONS}

The first solid-state method to prepare $\mathrm{Au} / \mathrm{Ag}$ superstructures is reported. Chitosan(MLn/M'Ln) and PSP-4-PVP $\times\left(\mathrm{MLn} / \mathrm{M}^{\prime} \mathrm{Ln}\right) \mathrm{n}$ with $\mathrm{MLn}=\mathrm{AuCl}_{3}$ and $\mathrm{M}^{\prime} \mathrm{Ln}=\mathrm{Ag}\left(\mathrm{CF}_{3} \mathrm{SO}_{3}\right)$ are convenient precursors to superlattices $\mathrm{Au} / \mathrm{Ag}$ materials. The morphology of the "foams like" products depends both on the nature of the polymer as well as to the molar ratio polymer/metallic salt. The polymer PSP-4-PVP and the ratio 1.1 induce the most porous morphologies. The probable mechanism involves the formation of a cross-linking matrix with subsequent combustion of the organic matter where the bimetallic foams grow.

\section{ACKNOWLEDGMENTS}

To Fondecyt No 1120179 for financial support.

\section{REFERENCES}

1. R. Sardar, A.M. Funston, P. Mulvaney and R.W.Murray Langmuir, 25, 138, (2009).

2. G. Schmid and B. Corain Eur. J. Inorg. Chem. 3081, (2003).

3. M. Ch. Daniel and D. Astruc Chem. Rev. 104, 293, (2004).

4. Y.F.Wan, N.Goubet, P.A. Albouy and M.P. Pileni Langmuir DOI: dx.doi. org/10.1021/la3045187

5. M. P. Pileni Acc.Chem.Res. 40, 685, (2007).

6. M.P. Pileni J. Chem.Mater. 21, 16748, (2011).

7. C. Díaz and M. L. Valenzuela J. Chil. Chem. Soc. 50, 417, (2005).

8. C. Díaz, P. Castillo and M. L. Valenzuela J. Cluster. Science 16, 515, (2005).

9. C. Díaz and M. L. Valenzuela, J. Inorg. Organomet. Polym. Mater. 16, 123, (2006)
10. C. Díaz and M. L. Valenzuela Macromolecules 39, 103, (2006).

11. C. Díaz and M. L. Valenzuela J. Inorg. Organomet. Polym. Mater.16, 211, (2006).

12. C. Díaz and M. L. Valenzuela J. Inorg. Organomet. Polym. Mater. 16 419, (2006).

13. C. Díaz, M. L. Valenzuela, L. Zuñiga, C. O’Dwyer, J. Inorg. Organometallic. Polymer 19, 507, (2009).

14. C. Diaz, M. L. Valenzuela, D. Bravo, V. Lavayen and C. O’Dwyer Inorg. Chem. 47, 11561, (2008)

15. C. Díaz, M. L. Valenzuela, E. Spodine, Y. Moreno and O. Peña J. Cluster Science 18, 831, (2007)

16. J. Jimenez, A. Laguna, M. Benouazzane, J. A. Sanz, C. Díaz, M. L. Valenzuela, P. G. Jones Chem. Eur. J. 15, 13509, (2009).

17. C. Diaz, M. L. Valenzuela, A. Laguna, V. Lavayen, J. Jimenez, L. Power and C. O'Dwyer Langmuir 26,10223, (2010).

18. C. Diaz, V. Lavayen, and C. O'Dwyer J. Solid State Chemistry 183, 1595 , (2010).

19. C. Diaz, M. L.Valenzuela, D. Bravo, C. Dickinson and C. O’Dwyer Journal of Colloide and Interface Science 362, 21, (2011).

20. C. Diaz, M. L. Valenzuela, V. Lavayen, K. Mendoza, O. Peña, C. O’Dwyer Inorganica Chimica Acta 377, 5, (2011).

21. C. Díaz, M. L. Valenzuela and N. Yutronic Journal of Inorganic and Organometallic Polymers 17, 577, (2007).

22. K. Ogawa and K. Oka Chem. Mater. 5, 726, (1993).

23. S. Schlick Macromolecules 19, 192, (1986).

24. R. Hernandez, O. Reyes and A.R. Rumalho J. Braz. Chem.Soc. 18, 1388. (2007).

25. P. Guo, W. Wenyan, G. Liang and P. Yao J. Colloid. Interf. Sci. 323, 229 (2008).

26. L. A. Belfiore, M. Pat Curdie and E. Ueda Macromolecules 26, 6908, (1993).

27. A. Haynes, P. M. Maitlis, R. Quyoum, C. Pulling, H. Adams, S. E. Spey, and R.W. Strange J. Chem. Soc. Dalton Trans. 2565, (2002).

28. C. V. Franco, M. M. da SilvaPaula, G. Goulart, L. F. De Lima, L. K. Noda and N. S. Goncalves Mater. Letters 60, 2549, (2006).

29. M. Antonietti, E. Wenz, L. Bronstein and M. Seregina Adv. Mater. 7 , 1000, (1995).

30. M. Tsuji, R. Matsuo, P. Jiang, N. Miyamae, D. Ueyama, M.Nishio, S. Hikino, H. Kumagae, K. Sozana and X. L. Tang Crystal Growth and Design 8, 2528, (2008).

31. X. Liu, A. Wang, X. Yang, T. Zhang, Ch.Y. Mou, D. Sh. Su and J. Li Chem.Mater. 21, 410, (2009).

32. Sh. Tokonami, N. Morita, K. Takasaki and N. Toshima J. Phys.Chem. C. 114, 10336, (2010).

33. T. Shibata, B.A. Bunker, Z. Zhang,D.Meisel, Ch. F. Vardeman II and J. D. Gezelter J. Am. Chem.Soc. 124, 11989, (2002).

34. J. H. Hodak, A. Henglein, M. Giersig and G.V. Hartland J. Pys. Chem. B 104, 11708-11718, (2000)

35. L. M. Liz-Marzan and A. P. Philipse J. Phys. Chem. 99, 15120-15128, (1995).

36. A. V. Singh, B. M. Bandgar, M. Kasture, B. L. Prasad and M. Sastry J. Mater. Chem. 15, 5115, (2005).

37. O. M. Wilson, R. W. J. Scott, J. C. Garcia-Martinez and R. M Crooks J. Am.Chem.Soc. 127, 1015-1024, (2005).

38. S. Anandan, F. Grieser and M. Ashokkumar Toshima J. Phys.Chem. C. 112, 15102, (2008).

39. J. He, I. Ichinose, T. Kunitake, A. Nakao, Y. Shiraishi and N. Toshima J. Am. Chem. Soc. 125, 11034,(2003).

40. J. Biener, A. Wittstock, L. A. Zepeda-Ruiz, M. M. Biener, V. Zielasek, D. Kramer, R. N. Viswanath, J. K. Weissmuller, M. Baumer, A. V. Hamza Nature Materials 28, 47, (2009).

41. L. Lefebvre, J. Banhart, D. Dunand Porous Metals and metallic Foams: Current status and recent Developments. Advanced Engineering Materials 10, 775, (2008).

42. J. Q. Pratik Motwani, M. Gheewala, Ch. Brennan, J. C. Wolfe and W. Ch. Shih Nanoscale 5, 4105, (2013)

43. C. Diaz, M.L. Valenzuela, V. Lavayen, and O'Dwyer Inorganic Chemistry 51, 6228 (2012)

44. B. Tappan, M.H. Huynh, M. A. Hiskey, D.E. Chavez, E.P. Luther, J.T. Mang and S.F. Son. J Am Chem Soc 128, 6589, (2006). 